\title{
ANALISA STRATEGI TEKNOLOGI INFORMASI PEMASARAN UKM KULINER DI MEDIA SOSIAL MENGGUNAKAN METODE SWOT
}

\author{
Fahmi Ajismanto*1, Andika Widyanto ${ }^{2}$ \\ ${ }^{1,2}$ Sistem Informasi, STMIK Palcomtech \\ Email: ${ }^{1}$ fahmi_ajismanto@palcomtech.ac.id, ${ }^{2}$ andika_widyanto@palcomtech.ac.id \\ "Penulis Korespondensi
}

(Naskah masuk: Juli 2020, diterima untuk diterbitkan: Agustus 2020)

\begin{abstract}
Abstrak
Penelitian ini bertujuan untuk menganalisis penggunaan media sosial sebagai media promosi usaha kuliner kecil dan menengah di Palembang. Suatu teknik pengambilan keputusan dalam promosi usaha kuliner menggunakan metode Strength, Weakness, Opportunities, and Threats (SWOT). Dengan mengetahui keempat aspek tersebut pelaku usaha dapat memaksimalkan kekuatan dari pemasaran melalui sosial media, meminimalkan kelemahan dan ancaman sosial media marketing, dan membangun peluang-peluang di masa depan. Penelitian ini menganalisis data secara kuantitatif dan kualitatif. Data kualitatif berupa pertanyaan-pertanyaan yang diajukan kepada responden penelitian dengan menggunakan kuesioner, kemudian data tersebut dikuantifikasi agar dapat dianalisis lebih dalam. Tahapan nya dari pemberian bobot dan rating, perhitungan IFAS dan EFAS, diagram kartesius swot, matriks strategi kombinasi strategi, dan matriks SWOT. Kuesioner diberikan kepada 60 pelaku UMKM dan juga pelanggan yang melihat konten promosi UMKM di media sosial. Dilihat dari hasil analisis SWOT diagram kartesius coordinate point antara internal factor dan external factor sebesar 0,19;-0,43 terletak pada kuadran IV yang artinya strategi diversifikasi perlu diterapkan. Strategi yang perlu diterapkan adalah ST strategi seperti menyeleksi target audiens yang melihat iklan berdasarkan range usia, dan jenis kelamin, kemudian implementasi search engine marketing (SEM) dan search engine optimization (SEO) lebih mendalam (S1, T1). Membuat hashtag ataupun keyword yang relevan dengan produk yang ditawarkan, membangun brand image (Personal Branding), dan membuat konten iklan yang menarik (S1, T1, T3). Terakhir, Lebih mengarahkan konsumen ke transaksi penjualan melalui marketplace ataupun website, dan gunakan rekening bersama (S4, T2). Penggunaan teknologi informasi sebagai media promosi di sosial media menjadi salah satu teknik pengambilan keputusan yang dibutuhkan dalam mempromosikan dan meningkatkan pendapatan UMKM di Palembang.
\end{abstract}

Kata kunci: SWOT, Media Sosial, Teknologi Informasi, UMKM

\section{INFORMATION TECHNOLOGY STRATEGY ANALYSIS OF CULINARY SME MARKETING IN SOCIAL MEDIA USING THE SWOT METHOD}

\begin{abstract}
The aim of this study is to determine the use of social media as a culinary promotions in Palembang. The technique method for making decisions in the promotion of Small Medium Culinary Enterpraise (Culinary SME's) used Strengths, Weaknesses, Opportunities, and Threats Analysis (SWOT). By understanding these four aspects, opportunities for marketing improvement through social media are needed, discussing the weaknesses and challenges of social media marketing, and building opportunities in the future. This study analyzes data quantitatively and qualitatively. Qualitative data in this research is the form of questions asked to respondents using a questionnaire, then the data are quantified for in depth analysis. The stages are from weighting and rating every item in questionneire, IFAS and EFAS calculations, Cartesian SWOT diagrams, combined strategy matrice, and SWOT matrices. Questionnaires were given to 60 Culinary SME's, and also customers who viewed promotional content on social media. From the results of the SWOT analysis the Cartesian coordinate point diagram between internal factors and external factors is 0.19 ; -0.43 in quadrant $I V$, which means that a diversification strategy needs to be applied. Strategies that need to be implemented are ST strategies such as selecting the target audience who see ads based on age range, and gender, then the implementation of search engine marketing (SEM) and search engine optimization (SEO) more deeply (S1, T1). Create hashtags or keywords that are relevant to the products offered, build a brand image (Personal Branding), and create interesting advertising content (S1, T1, T3). Finally, more direct consumers to sales transactions through the marketplace or website, and use a joint account (S4, T2). The used of information technology as a promotional media on social
\end{abstract}


media is one of the decision-making techniques needed to promote and increase the income of Culinary SMEs in Palembang

Keywords: SWOT, Social Media, Information Technoloy, Culinary SME's

\section{PENDAHULUAN}

Kota Palembang yang merupakan ibukota dari Provinsi Sumatera Selatan terpilih menjadi salah satu Kota Kreatif 2019 pada sub sektor unggulan kuliner dengan ekosistem ekonomi kreatif terbaik untuk kota di luar Pulau Jawa. Keberanekaragaman kuliner khas di Palembang menjadi salah satu kekuatan ekonomi kreatif di Palembang. Pesatnya pertumbuhnya usaha makanan kecil dan menengah menjadi roda penggerak ekonomi rakyat (Badan Ekonomi Kreatif, 2019). Namun sayangnya, UKM tidak memaksimalkan pemanfaatan potensi dari alat digital baru saat ini, dan tidak memperoleh manfaat dari peluang perkembangan teknologi informasi sekarang ini sebagai media pemasaran digital (Maarit \& Heikki, 2015). Hal ini dikarenakan kurangnya pemahaman terhadap penggunaan alat digital itu sendiri. Implementasi penggunaan teknologi informasi yang banyak dilakukan oleh UKM kebanyakkan hanya dengan menggunakan media digital seperti email, website dan media sosial sebagai alat komunikasi pemasaran mengenalkan produk dan melakukan penjualan (Yoga et al., 2019). Meskipun demikian, ini merupakan langkah awal yang baik untuk UMKM dalam pemanfaatan teknologi sebagai media pemasaran dan penjualan. Dikarenakan era industri 4.0 media sosial menjadi suatu wadah baru dalam meningkatkan keuntungan dan pemasaran (Sinha \& Singh, 2018). Industri 4.0 secara tidak langsung menuntut para pelaku usaha beralih dari sistem pemasaran dan penjualan tradisional menjadi lebih digital, khususnya penggunaan media sosial sebagai media promosi dan penjualan (Sinha \& Singh, 2018). Sistem dan teknologi informasi adalah salah satu faktor yang mempengaruhi suatu organisasi. Karena sistem dan teknologi informasi yang akan terus berkembang, suatu organisasi memerlukan perencanaan strategis (Utami et al., 2018). Dengan demikian sangat penting bagi UMKM memiliki rencana strategis.

Perencanaan strategi pemasaran yang baik dimulai dari mengetahui faktor internal dan eksternal dari usaha itu sendiri. Menganalisis faktor internal yang dalam hal ini mengetahui kekuatan dan kelemahan yang dapat membantu entitas memahami sumber daya apa saja yang dimiliki, yang memberikan profit dan dapat bersaing dengan kompetitor. Menggali lebih luas faktor eksternal agar entitas dapat mengidentifikasi ancaman dan peluang di lingkungakan bisnis yang kompetitif (Gürel, 2017). Analisis faktor internal dan eksternal ini dikenal dengan analisis strength, weakness, opportunity, and threats (SWOT) yang bisa mempengaruhi kinerja bisnis (Namugenyi et al., 2019). Strength dan
Weakness adalah faktor internal dan keunikan entitas, Opportunities, dan Threats adalah faktor eksternal dan ciri lingkungan luar. SWOT telah digunakan oleh banyak praktisi, peneliti pemasaran, dan merupakan alat yang sering dan populer digunakan mahasiswa pemasaran. Kesederhanaan dari SWOT dan akronim yang menarik penggunaannya dalam bisnis (Helms \& Nixon, 2010).

SWOT digunakan untuk menilai alternatif dan situasi keputusan yang kompleks. Di arena bisnis pengelompokan masalah internal dan eksternal adalah titik awal yang sering dilakukan untuk perencanaan strategis (Helms \& Nixon, 2010). Metode SWOT digambarkan dengan memiliki empat kuadran yang memungkinkan untuk dirangkum dan disesuaikan dengan tiap-tiap bagian (Gürel, 2017). Strength yang dimiliki entitas terdiri dari kemampuani entitas yang berperan aktif mencapai tujuan entitas. Sebelum menghadapi masalah dan melihat peluang, entitas harus mengetahui potensi yang dimilikinya dan aspek-aspek yang membuatnya lebih diuntungkan daripada entitas pesaing (Helms \& Nixon, 2010). Memiliki kekuatan sangat penting bagi suatu entitas, hal ini agar setiap peluang yang diciptakan oleh lingkungan luar dapat dimanfaatkan dengan baik. Entitas harus dapat beradaptasi terhadap ancaman lingkungan luar dengan menggunakan kekuatannya. Strength factor menjadi kunci penting yang harus dipahami oleh entitas itu sendiri (Ülgen \& Mİrze, 2010). Analisis SWOT dapat membantu UMKM mengetahui apakah sistem pemasaran yang dilakukan di media sosial dapat memberikan keuntungan bagi usaha, serta mengevaluasi kelemahan. Analisis ini juga memberikan gambaran mengenai peluang dan ancaman apa saja yang mungkin terjadi dari pemasaran di media sosial yang harus dihadapi oleh UMKM (Namugenyi et al., 2019).

Berdasarkan fenomena masalah yang ada, penelitian ini dilakukan untuk menganalisis dan memberikan rekomendasi sistem pemasaran online berbasis media sosial pada UMKM di Palembang dengan menggunakan analisis SWOT. Penelitian ini melibatkan 60 pelaku usaha kuliner di Palembang dan juga customer yang mengisi form kuesioner. Penelitian ini memiliki tahapan-tahapan dimulai dari kuantifikasi data kualitatif berupa kuesioner, uji validitas dan realibilitas terhadap pertanyaan kuesioner, setelah itu melakukan perhitungan bobot dan pemberian rating faktor internal dan eksternal, perhitungan matriks IFAS dan EFAS, kemudian penjelasan menggunakan diagram kartesius SWOT dan matriks SWOT. Hasil dari penelitian ini berupa rekomendasi strategi pemasaran berbasis pemasaran 
di media sosial yang dapat diterapkan oleh UMKM di Palembang.

\section{METODE PENELITIAN}

Penelitian ini menggunakan analisis swot dengan pendekatan kuantitatif dan kualitatif sebagai strategi atau teknik pengambilan keputusan dalam promosi kuliner di media sosial. Dengan mengetahui strength, weakness, oppurtunites, dan threats (SWOT) pelaku usaha dapat memaksimalkan kekuatan dari pemasaran melalui sosial media, meminimalkan kelemahan dan ancaman sosial media marketing, dan membangun peluang-peluang di masa depan.

Pendekatan kualitatif dilakukan untuk menganalisis faktor-faktor lainnya yang tidak dapat dijelaskan secara kuantitatif (Sugiyono, 2016). Data pada penelitian ini berupa kuesioner yang diberikan kepada responden penelitian yang kemudian di kuantitatifkan untuk mengetahui besaran skor agar didapatkan hasil perhitungan analisis SWOT. Hasil perhitungan analisis SWOT berupa data angka dan rekomendasi strategi promosi di media sosial. Hasil ini dianalisis kembali untuk mengetahui lebih rinci strategi promosi media sosial terbaik yang direkomendasikan untuk UMKM di Palembang. Penelitian ini menggunakan random sampling dalam menentukan responden dimana kuesioner disebar ke total populasi sebesar 544 pelaku usaha kuliner Palembang yang terdaftar di BEKRAF, hanya 60 pelaku usaha yang dapat dijadikan sampel penelitian. Kuesioner berisi pernyataan mengenai factor internal dan eksternal yang kemudian dilakukan uji validitas dan realibilitas yang dibantu dengan aplikasi SPSS 22 untuk menguji validitas setiap pernyataan yang diajukan. Validitas instrumen penelitian yang baik menunjukan alat ukur untuk mendapatkan data tersebut dapat digunakan (Sugiyono, 2016). Uji validitas menggunakan kaidah keputusan bila $\mathbf{r}$ hitung $>r$ tabel maka data dinyatakan valid.

Faktor strength sistem pemasaran melalui media sosial memiliki kekuatan yang memiliki dampak terhadap entitas (Suguna \& Selladurai, 2019). Berikut strength yang dimaksud:

1. Lebih mudah mencapai target pemasaran dengan digital marketing dan lebih hemat biaya pemasaran

2. Iklan dapat di edit berulang kali dan informasi yang disampaikan lebih efektif dibandingkan dengan menggunakan brosur atau leaflet

3. Cakupan pasar lebih luas/ secara global

4. UMKM dapat mempromosikan produknya dengan biaya promosi yang lebih efisien

5. Transaksi yang dilakukan lebih cepat, efisien, dan efektif.

Weakness atau kelemahan mengacu pada tidak memiliki bentuk dan kompetensi diperlukan untuk sesuatu. Kelemahan berarti bahwa ada sesuatu yang lebih tidak menguntungkan jika dibandingkan dengan sesuatu yang lain. Dalam hal ini, kelemahan adalah karakteristik yang negatif dan tidak menguntungkan (Gürel, 2017). Pada penelitian ini kelemahan pada pemasaran di media sosial dipengaruhi oleh beberapa hal berikut ini:

1. Pemahaman mengenai penggunaan teknologi dan terus mengikuti perkembangannya

2. Pengetahuan lebih mendalam mengenai perilaku, selera, dan yang lebih di sukai konsumen

3. Tidak menjangkau orang-orang yang tidak menggunakan internet

4. Dampak negatif ulasan konsumen di dunia online yang tidak dapat di kontrol

5. Persaingan lebih ketat.

Oppurtunity atau peluang yang merupakan bagian penting agar UMKM dapat bersaing di era digital saat ini, hal ini dilihat dari:

1. Mendorong pertumbuhan UMKM lebih pesat

2. Meningkatkan citra brand yang mendorong peningkatan pendapatan

3. Terciptanya wilayah digital yang segalanya lebih cepat dan memudahkan

4. Dapat menganalisis kompetitor

5. Semakin meningkatnya pengguna media sosial, semakin meningkatkan peluang pasar

Threats atau ancaman berupa perubahan keadaan yang setiap perubahannya memiliki dampak yang besar bagi UMKM:

1. Bila salah dalam menentukan target pasar, akan berdampak langsung pada peluang bisnis

2. Kerahasiaan data pengguna masih menjadi isu yang dipertanyakan

3. Kasus penipuan lebih tinggi

4. Ulasan yang buruk menggenai UMKM yang sulit untuk dihilangkan dan dapat mempengaruhi usaha kedepannya

5. Butuh usaha yang lebih untuk mendapatkan kepercayaan konsumen

Penelitian ini juga melakukan pemberian rating pada setiap item pernyataan kuesoioner dan pembobotan nilai factor internal dan eksternal agar data dapat diolah secara kuantitatif dengan rumus table 1 .

Tabel 1. Perhitungan Bobot Faktor Internal dan Eksternal

\begin{tabular}{lc}
\hline Internal & total jawaban responden \\
\cline { 2 - 2 } Eksternal & total pengolahan data faktor internal \\
& $\frac{\text { total pengolahan data faktor eksternal }}{}$
\end{tabular}

Sumber: (David \& R, 2009).

Dilanjutkan dengan perhitungan matriks IFAS untuk mengetahui kekuatan dan kelemahan sosial media sebagai media promosi dan matriks EFAS yang dapat memberikan gambaran mengenai kesempatan dan ancaman pada table 2 . 


\begin{tabular}{|c|c|c|}
\hline \multirow{2}{*}{\multicolumn{2}{|c|}{ Rating IFAS }} & total jawaban responden IFAS \\
\hline & & $\begin{array}{c}\text { jumlah responden } \\
\end{array}$ \\
\hline $\begin{array}{l}\text { Perhitungan } \\
\text { IFAS }\end{array}$ & Skor & $\begin{array}{l}\text { Bobot (factor internal) } \mathrm{X} \text { rating } \\
\text { IFAS }\end{array}$ \\
\hline Rating EFAS & & total jawaban responden EFAS \\
\hline $\begin{array}{l}\text { Perhitungan } \\
\text { EFAS }\end{array}$ & Skor & $\begin{array}{l}\text { jumlah responden } \\
\text { Bobot (factor internal) X rating } \\
\text { EFAS }\end{array}$ \\
\hline
\end{tabular}

Sumber: (David \& R, 2009).

Pemetaan hasil perhitungan matriks IFAS dan EFAS digambarkan pada diagram Cartesius SWOT. Dimana sumbu horizontal memberikan informasi kekuatan dan kelemahan (kordinat analisis internal), sedangkan sumbu vertical memberikan informasi mengenai kesempatan dan ancaman (kordinat analisis eksternal) (David \& R, 2009). Secara matematis dituangkan seperti ini:

\section{Kordinat analisis internal ; Kordinat analisis eksternal}

Untuk mendapatkan titik kordinat diagram Cartesius analisis SWOT menggunakan rumus sebagai berikut:

(total skor kekuatan - kelemahan); (total skor kesempatan total skor ancaman)

Setelah melakukan tahapan analisis yang telah dijelaskan, kemudian mendapatkan titik kordinat cartesius dan dituangkan dalam diagram cartersius, langkah selanjutnya adalah mengolah data menggunakan rumus kombinasi alternatif strategi SO, ST, WO dan WT yang hasil analisisnya akan dituangkan dalam bentuk matriks.

\section{HASIL DAN PEMBAHASAN}

\subsection{Uji validitas dan realibilitas}

Penelitian ini dibantu alat analisis statistik SPSS 22. Hasil uji validitas menunjukkan hasil sebagai berikut:

Tabel 3. Hasil Uji Validitas

\begin{tabular}{cccc}
\multicolumn{4}{c}{ Tabel 3. Hasil Uji Validitas } \\
\hline PERNY- & r & r & KETERANGAN \\
ATAAN & HITUNG & TABEL & \\
\hline S1 & 0,552 & 0,25 & VALID \\
S2 & $0,610^{* *}$ & 0,25 & VALID \\
S3 & 0,629 & 0,25 & VALID \\
S4 & $0,335^{* *}$ & 0,25 & VALID \\
S5 & $0,608^{* *}$ & 0,25 & VALID \\
W1 & 0,268 & 0,25 & VALID \\
W2 & $0,258^{*}$ & 0,25 & VALID \\
W3 & $-0,117$ & 0,25 & TIDAK VALID \\
W4 & $-0,254$ & 0,25 & TIDAK VALID \\
W5 & $0,593^{* *}$ & 0,25 & VALID \\
O1 & 0,081 & 0,25 & TIDAK VALID \\
O2 & $0,366^{* *}$ & 0,25 & VALID
\end{tabular}

\begin{tabular}{cccc}
\hline $\begin{array}{c}\text { PERNY- } \\
\text { ATAAN }\end{array}$ & $\begin{array}{c}\mathbf{r} \\
\text { HITUNG }\end{array}$ & $\begin{array}{c}\text { TABEL } \\
\text { KETERANGAN }\end{array}$ \\
\hline O3 & $-0,034$ & 0,25 & TIDAK VALID \\
O4 & $0,513^{* *}$ & 0,25 & VALID \\
O5 & $0,257^{*}$ & 0,25 & VALID \\
T1 & 0,261 & 0,25 & VALID \\
T2 & $-0,001$ & 0,25 & TIDAK VALID \\
T3 & $0,472^{* *}$ & 0,25 & VALID \\
T4 & $0,331^{* *}$ & 0,25 & VALID \\
T5 & $0,339^{* *}$ & 0,25 & VALID
\end{tabular}

Sumber: Data diolah, 2020.

Tabel 3 memberikan informasi hasil uji validitas setiap item pernyataan. Dari hasil tersebut lima pernyataan yang tidak valid yakni W3, W4, O1, O3, dan T2. Tidak validnya kelima pernyataan tersebut mengindikasikan tidak dapatnya pernyataan tersebut sebagai alat ukur pada penelitian ini. Alat ukur yang tidak valid tersebut dikeluarkan dari penelitian dan tidak dimasukkan dalam tahapan uji realibilitas dan tahapan analisis selanjutnya.

\begin{tabular}{|c|c|c|c|c|c|}
\hline & $\begin{array}{c}\text { Scale } \\
\text { Mean } \\
\text { if Item } \\
\text { Dele- } \\
\text { ted }\end{array}$ & $\begin{array}{c}\text { Scale } \\
\text { Varian } \\
\text { ce if } \\
\text { Item } \\
\text { Dele- } \\
\text { ted }\end{array}$ & $\begin{array}{c}\text { Correc } \\
\text { ted } \\
\text { Item- } \\
\text { Total } \\
\text { Correl } \\
\text { ation }\end{array}$ & $\begin{array}{c}\text { Cronb } \\
\text { ach's } \\
\text { Alpha } \\
\text { if Item } \\
\text { Dele- } \\
\text { ted }\end{array}$ & Keterangan \\
\hline S1 & 48,48 & 15,949 &, 559 &, 650 & Reliable \\
\hline S2 & 48,50 & 15,339 & ,591 & 640 & Reliable \\
\hline S3 & 48,40 & 15,769 & ,598 & ,645 & Reliable \\
\hline $\mathrm{S} 4$ & 48,55 & 16,964 & ,335 & 674 & Reliable \\
\hline S5 & 48,70 & 15,400 &, 544 & ,645 & Reliable \\
\hline W2 & 48,57 & 17,741 & ,112 & ,698 & Reliable \\
\hline W5 & 48,62 & 15,427 & ,626 & ,639 & Reliable \\
\hline $\mathrm{O} 2$ & 48,72 & 17,325 & 197 & ,688 & Reliable \\
\hline $\mathrm{O} 4$ & 48,95 & 16,014 &, 347 & ,670 & Reliable \\
\hline O5 & 48,67 & 16,972 & ,182 & ,694 & Reliable \\
\hline $\mathrm{T} 3$ & 48,72 & 15,766 &, 345 & ,671 & Reliable \\
\hline $\mathrm{T} 4$ & 48,95 & 17,303 & , 106 &, 707 & Reliable \\
\hline $\mathrm{T} 5$ & 48,65 & 16,943 & ,236 & ,684 & Reliable \\
\hline W1 & 48,42 & 18,891 &,- 098 & ,713 & Reliable \\
\hline $\mathrm{T} 1$ & 48,75 & 18,123 &, 014 &, 713 & Reliable \\
\hline
\end{tabular}

Sumber: Data diolah, 2020.

Dari tabel 4 diketahui setiap item pernyataan pada penelitian ini reliable. Dengan demikian didapatkan 15 item pernyataan yang dijadikan alat ukur analisis SWOT pada penggunaan teknologi informasi media sosial UMKM kota Palembang. Data tersebut kemudian dianalisis ke tahapan selanjutnya untuk di kuantifikasi.

\subsection{Perhitungan bobot faktor internal dan eksternal}


Perhitungan bobot faktor internal dan eksternal dilakukan agar data penelitian dapat dianalisis secara kuantitatif dengan menggunakan diagram cartesius sebagai media informasi hasil penelitian.

\begin{tabular}{|c|c|c|c|}
\hline \multicolumn{2}{|r|}{ Pernyataan } & \multirow{2}{*}{$\begin{array}{l}\text { Pengolahan } \\
\text { Data } \\
\text { Kuesioner }\end{array}$} & \multirow[t]{2}{*}{ Bobot } \\
\hline & Strength & & \\
\hline 1 & $\begin{array}{lr}\text { Lebih } & \text { mudah } \\
\text { mencapai } & \text { target } \\
\text { pemasaran dengan } & \text { digital marketing dan } \\
\text { lebih hemat biaya } \\
\text { pemasaran }\end{array}$ & 218 & 0,104008 \\
\hline 2 & $\begin{array}{l}\text { Iklan dapat di edit } \\
\text { berulang kali dan } \\
\text { informasi } \\
\text { disampaikan lebih } \\
\text { efektif dibandingkan } \\
\text { dengan menggunakan } \\
\text { brosur atau leaflet }\end{array}$ & 217 & 0,103531 \\
\hline 3 & $\begin{array}{l}\text { Cakupan pasar lebih } \\
\text { luas/ secara global }\end{array}$ & 223 & 0,106393 \\
\hline 4 & $\begin{array}{l}\text { UMKM dapat } \\
\text { mempromosikan } \\
\text { produknya dengan } \\
\text { biaya promosi yang } \\
\text { lebih efisien }\end{array}$ & 214 & 0,102099 \\
\hline 5 & $\begin{array}{l}\text { Transaksi yang } \\
\text { dilakukan lebih cepat, } \\
\text { efisien, dan efektif }\end{array}$ & 205 & 0,097805 \\
\hline & Total Kekuatan & 1077 & 0,513836 \\
\hline \multicolumn{4}{|c|}{ Weakness } \\
\hline 1 & $\begin{array}{l}\text { Harus memahami } \\
\text { penggunaan teknologi } \\
\text { dan terus mengikuti } \\
\text { perkembangannya }\end{array}$ & 222 & 0,105916 \\
\hline 2 & $\begin{array}{l}\text { Harus mengetahui } \\
\text { lebih mendalam } \\
\text { mengenai perilaku, } \\
\text { selera, dan yang lebih } \\
\text { di sukai konsumen }\end{array}$ & 213 & 0,101622 \\
\hline \multirow[t]{3}{*}{3} & Persaingan lebih ketat & 210 & 0,100191 \\
\hline & Total Kelemahan & 1019 & 0,486164 \\
\hline & Total Internal & 2096 & 1 \\
\hline
\end{tabular}

Sumber: Data diola, 2020 2096.

Dari tabel 5 diketahui skor total faktor internal sebesar

Penjumlahan dari faktor strength sebesar 1077 dan weakness sebesar 1019. Faktor strength pada penelitian ini lebih besar daripada faktor weakness atau kelemahan. Artinya, penggunaan teknologi informasi media sosial sebagai media promosi UMKM di Palembang memiliki dampak yang positif bagi para pelaku UMKM dalam memasarkan produknya dan para pelaku UMKM dapat mengatasi kelemahan dari penggunaan teknologi informasi itu sendiri.

Total faktor opportunity di tabel 6 menunjukkan skor 601 lebih kecil daripada total faktor threats sebesar 804. Hal ini menunjukkan faktor eksternal berupa ancaman yang akan dihadapi oleh UMKM di Palembang dalam penggunaan teknologi informasi media sosial sebagai media promosi lebih besar daripada peluang yang dimiliki.

\begin{tabular}{|c|c|c|c|}
\hline & Pernyataan & $\begin{array}{c}\text { Pengolahan } \\
\text { Data } \\
\text { Kuesioner }\end{array}$ & Bobot \\
\hline \multicolumn{4}{|c|}{ Opportunity } \\
\hline 1 & $\begin{array}{l}\text { Meningkatkan } \\
\text { citra brand yang } \\
\text { mendorong } \\
\text { peningkatan } \\
\text { pendapatan }\end{array}$ & 204 & 0,145196 \\
\hline 2 & $\begin{array}{l}\text { Dapat } \\
\text { menganalisis } \\
\text { kompetitor }\end{array}$ & 190 & 0,135231 \\
\hline 3 & $\begin{array}{l}\text { Semakin } \\
\text { meningkatnya } \\
\text { pengguna media } \\
\text { sosial, semakin } \\
\text { meningkatkan } \\
\text { peluang pasar }\end{array}$ & 207 & 0,147331 \\
\hline & $\begin{array}{l}\text { Total Peluang } \\
\text { Threats }\end{array}$ & 601 & 0,427758 \\
\hline 1 & $\begin{array}{l}\text { Bila salah dalam } \\
\text { menentukan target } \\
\text { pasar, akan } \\
\text { berdampak } \\
\text { langsung pada } \\
\text { peluang bisnis }\end{array}$ & 202 & 0,143772 \\
\hline 2 & $\begin{array}{l}\text { Kasus penipuan } \\
\text { lebih tinggi }\end{array}$ & 204 & 0,145196 \\
\hline 3 & $\begin{array}{l}\text { Ulasan yang buruk } \\
\text { menggenai } \\
\text { UMKM yang sulit } \\
\text { untuk dihilangkan } \\
\text { dan dapat } \\
\text { mempengaruhi } \\
\text { usaha kedepannya }\end{array}$ & 190 & 0,135231 \\
\hline 4 & $\begin{array}{l}\text { Butuh usaha yang } \\
\text { lebih untuk } \\
\text { mendapatkan } \\
\text { kepercayaan } \\
\text { konsumen }\end{array}$ & 208 & 0,148043 \\
\hline & Total Ancaman & 804 & 0,572242 \\
\hline & Total Eksternal & 1405 & 1 \\
\hline
\end{tabular}

Sumber: Data diola, 2020

\subsection{Perhitungan Bobot dan Rating Matriks}

Perhitungan matrik IFAS dilakukan untuk untuk menentukan bobot, rating dan skor dimana jumlah bobot tidak melebihi jumlah 1,00. Menghitung nilai rating masing-masing sosial dilakukan dengan memberikan skala 1 hingga 4 . Berikut adalah hasil perhitungan matrik IFAS pada Tabel 7.

Perhitungan matrik EFAS sama halnya dengan matrik IFAS yaitu untuk menentukan bobot, rating dan skor. Berikut adalah tabel hasil perhitungan matrik EFAS. Nilai rating kekuatan dan kelemahan selalu bertolak belakang, begitu juga dengan peluang dan ancaman.

Tabel 7. Perhitungan matriks Internal Factor Analysis Summary (IFAS)

\begin{tabular}{|c|c|c|c|c|c|}
\hline \multicolumn{6}{|c|}{ Summary (IFAS) } \\
\hline No & Pernyataan & & Bobot & Rating & Skor \\
\hline & Strength & & & & \\
\hline 1 & $\begin{array}{l}\text { Lebih } \\
\text { mencapai } \\
\text { pemasaran } \\
\text { dengan } \\
\text { marketing }\end{array}$ & $\begin{array}{r}\text { mudah } \\
\text { target } \\
\begin{array}{r}\text { digital } \\
\text { dan }\end{array}\end{array}$ & 0,104008 & 4 & 0,416031 \\
\hline
\end{tabular}


1302 Jurnal Teknologi Informasi dan Ilmu Komputer (JTIIK), Vol. 7, No. 6, Desember 2020, hlm. 1297-1306

\begin{tabular}{|c|c|c|c|c|}
\hline \multirow[t]{3}{*}{ No } & Pernyataan & \multirow[t]{3}{*}{ Bobot } & \multirow[t]{3}{*}{ Rating } & \multirow[t]{3}{*}{ Skor } \\
\hline & Strength & & & \\
\hline & $\begin{array}{l}\text { lebih hemat biaya } \\
\text { pemasaran }\end{array}$ & & & \\
\hline 2 & $\begin{array}{l}\text { Iklan dapat di edit } \\
\text { berulang kali dan } \\
\text { informasi yang } \\
\text { disampaikan lebih } \\
\text { efektif } \\
\text { dibandingkan } \\
\text { dengan } \\
\text { menggunakan } \\
\text { brosur atau leaflet }\end{array}$ & 0,103531 & 4 & 0,414122 \\
\hline 3 & $\begin{array}{l}\text { Cakupan pasar } \\
\text { lebih luas/ secara } \\
\text { global }\end{array}$ & 0,106393 & 4 & 0,425573 \\
\hline 4 & $\begin{array}{l}\text { UMKM dapat } \\
\text { mempromosikan } \\
\text { produknya } \\
\text { dengan biaya } \\
\text { promosi yang } \\
\text { lebih efisien }\end{array}$ & 0,102099 & 4 & 0,408397 \\
\hline \multirow[t]{3}{*}{5} & $\begin{array}{l}\text { Transaksi yang } \\
\text { dilakukan lebih } \\
\text { cepat, efisien, dan } \\
\text { efektif }\end{array}$ & 0,097805 & 3 & 0,293416 \\
\hline & Total Kekuatan & 0,513836 & & 1,957538 \\
\hline & Weakness & & & \\
\hline 1 & $\begin{array}{l}\text { Harus memahami } \\
\text { penggunaan } \\
\text { teknologi dan } \\
\text { terus mengikuti } \\
\text { perkembangannya }\end{array}$ & 0,105916 & 4 & 0,423664 \\
\hline 2 & $\begin{array}{l}\text { Harus mengetahui } \\
\text { lebih mendalam } \\
\text { mengenai } \\
\text { perilaku, selera, } \\
\text { dan yang lebih di } \\
\text { sukai konsumen }\end{array}$ & 0,101622 & 4 & 0,406489 \\
\hline \multirow[t]{3}{*}{3} & $\begin{array}{l}\text { Persaingan lebih } \\
\text { ketat }\end{array}$ & 0,100191 & 4 & 0,400763 \\
\hline & Total Kelemahan & 0,486164 & & 1,766221 \\
\hline & Total Internal & 1 & & 3,72376 \\
\hline
\end{tabular}

Sumber: Data diolah, 2020.

Tabel 8. Perhitungan matriks Eksternal Factor Analysis Summary

\begin{tabular}{|c|c|c|c|c|}
\hline \multicolumn{5}{|c|}{ (EFAS) } \\
\hline & Opportunity & Bobot & Rating & Skor \\
\hline 1 & $\begin{array}{l}\text { Meningkatkan } \\
\text { citra brand yang } \\
\text { mendorong } \\
\text { peningkatan } \\
\text { pendapatan }\end{array}$ & 0,145196 & 3 & 0,435587 \\
\hline 2 & $\begin{array}{l}\text { Dapat } \\
\text { menganalisis } \\
\text { kompetitor }\end{array}$ & 0,135231 & 3 & 0,405694 \\
\hline \multirow[t]{3}{*}{3} & $\begin{array}{l}\text { Semakin } \\
\text { meningkatnya } \\
\text { pengguna media } \\
\text { sosial, semakin } \\
\text { meningkatkan } \\
\text { peluang pasar }\end{array}$ & 0,147331 & 3 & 0,441993 \\
\hline & Total Peluang & 0,427758 & & 1,283274 \\
\hline & Threats & & & \\
\hline 1 & $\begin{array}{l}\text { Bila salah dalam } \\
\text { menentukan } \\
\text { target pasar, akan } \\
\text { berdampak }\end{array}$ & 0,143772 & 3 & 0,431317 \\
\hline
\end{tabular}

\begin{tabular}{|c|c|c|c|c|}
\hline & Opportunity & Bobot & Rating & Skor \\
\hline & $\begin{array}{l}\text { langsung pada } \\
\text { peluang bisnis }\end{array}$ & & & \\
\hline 2 & $\begin{array}{l}\text { Kasus penipuan } \\
\text { lebih tinggi }\end{array}$ & 0,145196 & 3 & 0,435587 \\
\hline 3 & $\begin{array}{l}\text { Ulasan yang } \\
\text { buruk menggenai } \\
\text { UMKM yang } \\
\text { sulit untuk } \\
\text { dihilangkan dan } \\
\text { dapat } \\
\text { mempengaruhi } \\
\text { usaha } \\
\text { kedepannya }\end{array}$ & 0,135231 & 3 & 0,405694 \\
\hline 4 & $\begin{array}{l}\text { Butuh usaha yang } \\
\text { lebih untuk } \\
\text { mendapatkan } \\
\text { kepercayaan } \\
\text { konsumen }\end{array}$ & 0,148043 & 3 & 0,444128 \\
\hline & Total Ancaman & 0,572242 & & 1,716726 \\
\hline & Total Eksternal & 1 & & 3 \\
\hline
\end{tabular}

\subsection{Diagram Cartesius Analisis SWOT}

Tabel 7 matrik IFAS menunjukkan skor total kekuatan sebesar 1,957538 skor total kelemahan sebesar 1,766221. Skor total kekuatan lebih tinggi daripada skor total kelemahan, dengan demikian didapatkan hasil selisih sebesar 0,19. Sedangkan tabel 8 matrik EFAS menunjukkan total skor peluang sebesar 1,283274 dan skor total ancaman sebesar 1,716726 dengan selisih sebesar -0,43. Dari hasil perhitungan tersebut maka dapat digambarkan diagram cartesius sebagai berikut:

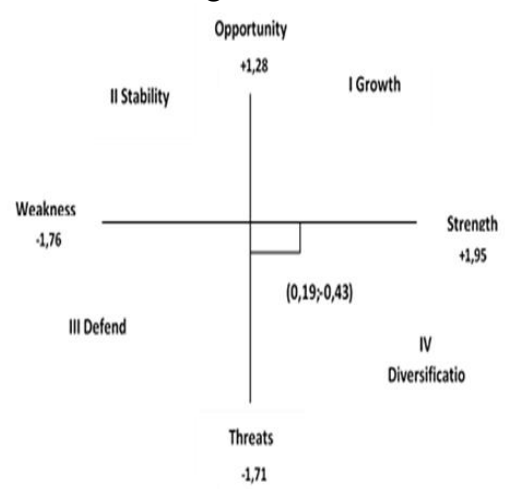

Sumber: Data diolah, 2020.

Gambar 1. Diagram Cartesius

Titik potong pada gambar 1 terletak pada kuadran keempat, dimana startegi diversifikasi perlu diterapkan dalam strategic planning pada penggunaan teknologi informasi media sosial sebagai media promosi UMKM di Palembang.

Strategi diversifikasi difokuskan pada penguatan bisnis utama atau menciptakan sumber daya yang mendukung (Şekerli \& Akçetin, 2018). Alasan utama untuk melakukan diversifikasi adalah untuk memaksimalkan nilai bisnis yang dimiliki terkadang dengan mengorbankan keunggulan kompetitif masing-masing unit bisnis (Orlando et al., 2018). Dalam kasus perusahaan dengan sumber daya yang memadai, melakukan diversifikasi penggunaan teknologi yang tidak terkait dengan peranan kunci pada kinerja perusahaan dapat dilakukan. Tingkat 
diversifikasi teknologi harus disesuaikan secara dinamis dalam kepatuhan dengan perubahan kemampuan inovasi perusahaan (Kook et al., 2017). Pelaku UMKM di Palembang dapat menggunakan teknologi informasi media sosial yang lainnya, tidak hanya youtube, instagram, dan facebook. Menggunakan marketplace sebagai salah satu langkah baru untuk memperluas pangsa pasar. Memanfaatkan iklan berbayar di media sosial ataupun menggunakan jasa influencer untuk mempromosikan produk kuliner, dan mulai memanfaatkan website dapat dilakukan oleh UMKM, meskipun menambah biaya promosi namun hal ini dapat dimasukkan sebagai investasi. Karena impact dari strategi promosi ini akan berpengaruh kepada penjualan dan pendapatan UMKM itu sendiri.

\subsection{Matriks SWOT}

Berbagai alternatif strategi dapat dirumuskan berdasarkan model analisis matriks SWOT. Strategi utama yang disarankan ada empat macam, yaitu SO, ST, WO, dan WT.

Tabel 9. Rumusan Kombinasi Strategi Matriks SWOT

\begin{tabular}{|c|c|c|}
\hline EFAS IFAS & Strength (S) & Weakness (W) \\
\hline Opportunities $(\mathrm{O})$ & $\begin{array}{l}\text { Strategy SO : } \\
=1,95+1,28 \\
=3,23\end{array}$ & $\begin{array}{l}\text { Strategy WO : } \\
=1,76+1,28 \\
=3,04\end{array}$ \\
\hline Threats $(\mathrm{T})$ & $\begin{array}{l}\text { Strategy ST: } \\
=1,95+1,71 \\
=3,66\end{array}$ & $\begin{array}{l}\text { Strategy WT: } \\
=1,76+1,71 \\
=3,47\end{array}$ \\
\hline
\end{tabular}

Sumber: Data diolah, 2020

Berdasarkan rumusan kombinasi strategi matriks SWOT pada Tabel 9. UMKM perlu memanfaatkan strategi ST dalam melakukan pemasaran di media sosial yang mempunyai nilai skor tertinggi yaitu 3,66. Diikuti dengan strategi WT = 3,47 , strategi $\mathrm{SO}=3,23$, dan strategi $\mathrm{WO}=3,04$.

Bila merujuk pada gambar 1, posisi strategi yang terbaik adalah diversifikasi. Hasil ini didukung dengan hasil rumusan kombinasi strategi matriks SWOT tabel 9, strategi utama yang dapat diterapkan adalah strategi strength-threats (ST). Analisis strategi pemasaran di media sosial yang dapat diterapkan UMKM dituangkan dalam tabel 10.

Tabel 10.Matriks SWOT Penggunaan Teknologi Informasi Media Sosial sebagai Media Promosi UMKM di Palembang

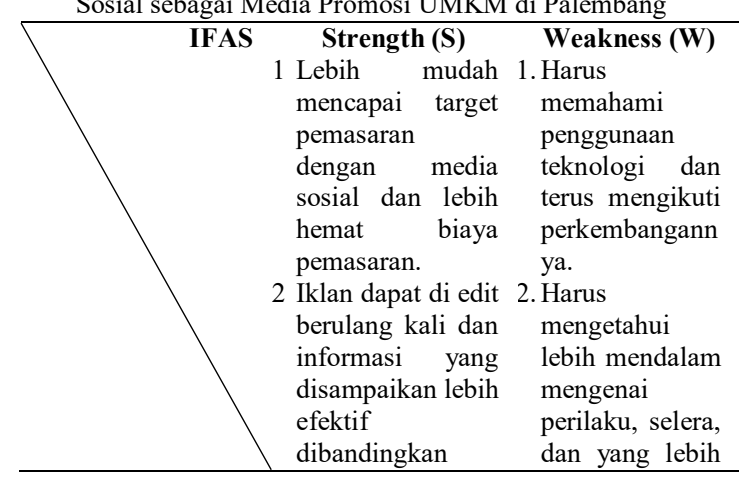

\begin{tabular}{|c|c|c|}
\hline EFAS & $\begin{array}{l}\text { dengan } \\
\text { menggunakan } \\
\text { brosur atau } \\
\text { leaflet. } \\
3 \text { Cakupan pasar } \\
\text { lebih luas/ secara } \\
\text { global. UMKM } \\
\text { dapat } \\
\text { mempromosikan } \\
\text { produknya } \\
\text { dengan biaya } \\
\text { promosi yang } \\
\text { lebih efisien. } \\
4 \text { Transaksi yang } \\
\text { dilakukan lebih } \\
\text { cepat, efisien, dan } \\
\text { efektif. }\end{array}$ & $\begin{array}{l}\text { di sukai } \\
\text { konsumen. } \\
\text { 3. Persaingan } \\
\text { lebih ketat }\end{array}$ \\
\hline $\begin{array}{l}\text { Opportunities }(\mathrm{O}) \\
\text { 1. Meningkatkan } \\
\text { citra brand yang } \\
\text { mendorong } \\
\text { peningkatan } \\
\text { pendapatan } \\
\text { 2. Dapat } \\
\text { menganalisis } \\
\text { kompetitor } \\
\text { 3. Semakin meningkatnya } \\
\text { mening } \\
\text { pengguna media } \\
\text { sosial, semakin } \\
\text { meningkatkan } \\
\text { peluang pasar }\end{array}$ & $\begin{array}{l}\text { SO Strategi } \\
\text { 1. Menambah slot } \\
\text { iklan di media } \\
\text { sosial dan } \\
\text { memperluas ke } \\
\text { pemasaran } \\
\text { digital lainnya } \\
\text { seperti website } \\
\text { dan email (S1, } \\
\text { S2, O1, O3) } \\
\text { 2. Melakukan } \\
\text { pemetaan pasar } \\
\text { dan pesaing } \\
\text { untuk } \\
\text { menentukan } \\
\text { positioning } \\
\text { iklan (S3, O2) } \\
\text { 3. Menerapkan } \\
\text { dan } \\
\text { menambahkan } \\
\text { sistem } \\
\text { pembayaran } \\
\text { online.Tidak } \\
\text { hanya cash atau } \\
\text { transfer bank, } \\
\text { menambahkan } \\
\text { e-money } \\
\text { lainnya (S4, O1) }\end{array}$ & $\begin{array}{l}\text { WO Strategi } \\
\text { 1. Mengikuti } \\
\text { seminar dan } \\
\text { pelatihan } \\
\text { mengenai } \\
\text { trend } \\
\text { penggunaan } \\
\text { teknologi } \\
\text { informasi } \\
\text { sebagai alat } \\
\text { pemasaran } \\
\text { digital (W1, } \\
\text { O1) } \\
\text { 2. Meningkatkan } \\
\text { pengetahuan } \\
\text { mengenai } \\
\text { strategi } \\
\text { pemasaran } \\
\text { (W2,O2,O3) } \\
\text { 3. Pelajari } \\
\text { mengenai } \\
\text { kompetitor } \\
\text { dan buatlah } \\
\text { inovasi sistem } \\
\text { pemasaran di } \\
\text { media sosial } \\
\text { (W3, O2) }\end{array}$ \\
\hline Threats (T) & ST Strategi & WT Strategi \\
\hline $\begin{array}{l}\text { 1. Bila salah dalam } \\
\text { menentukan target } \\
\text { pasar, akan } \\
\text { berdampak } \\
\text { langsung pada } \\
\text { peluang bisnis } \\
\text { 2. Kasus penipuan } \\
\text { lebih tinggi } \\
\text { 3. Ulasan yang } \\
\text { buruk menggenai } \\
\text { UMKM yang sulit } \\
\text { untuk dihilangkan } \\
\text { dan dapat } \\
\text { mempengaruhi } \\
\text { usaha kedepannya } \\
\text { Butuh usaha yang } \\
\text { lebih untuk } \\
\text { mendapatkan } \\
\text { kepercayaan } \\
\text { konsumen }\end{array}$ & $\begin{array}{l}\text { 1. Seleksi target } \\
\text { audiens yang } \\
\text { melihat iklan } \\
\text { berdasarkan } \\
\text { range usia, dan } \\
\text { jenis kelamin, } \\
\text { kemudian } \\
\text { implementasi } \\
\text { search engine } \\
\text { marketing dan } \\
\text { search engine } \\
\text { optimization } \\
\text { lebih mendalam } \\
\text { (S1, T1) } \\
\text { 2. Membuat } \\
\text { hashtag ataupun } \\
\text { keyword yang } \\
\text { relevan dengan } \\
\text { produk yang } \\
\text { ditawarkan, } \\
\text { membangun } \\
\text { brand image } \\
\text { (Personal } \\
\text { Branding), dan } \\
\text { membuat } \\
\text { konten iklan } \\
\text { yang menarik } \\
\text { (S1, T1, T3) }\end{array}$ & $\begin{array}{l}\text { 1. Bergabung } \\
\text { pada } \\
\text { komunitas } \\
\text { teknologi } \\
\text { informasi dan } \\
\text { pemasaran } \\
\text { khususnya } \\
\text { pada media } \\
\text { sosial (W1, } \\
\text { T1) } \\
\text { 2. Menerapkan } \\
\text { standarisasi } \\
\text { keamanan } \\
\text { sistem } \\
\text { informasi } \\
\text { seperti, } \\
\text { keamanan } \\
\text { data, kata } \\
\text { sandi, } \\
\text { gunakan } \\
\text { teknik } \\
\text { enkripsi dan } \\
\text { kriptograpi } \\
\text { (W1, T2) } \\
\text { 3. Menjaga } \\
\text { konsistensi } \\
\text { posting iklan } \\
\text { di media } \\
\text { sosial, }\end{array}$ \\
\hline
\end{tabular}




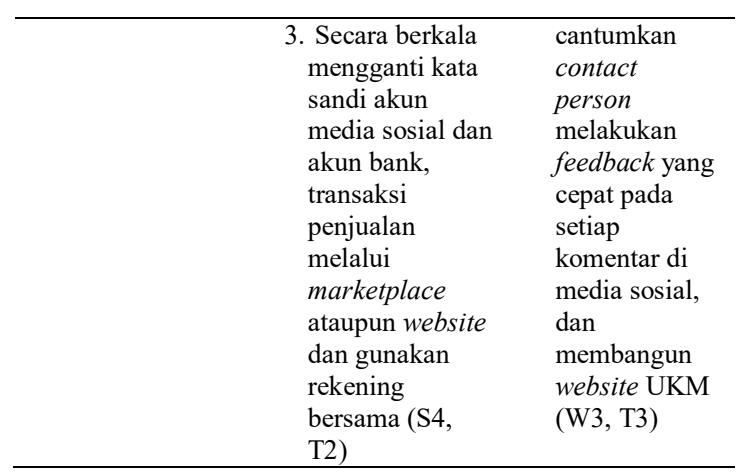

Sumber: Data diolah, 2020.

Strategi ST menggunakan kekuatan perusahaan untuk menghindari atau mengurangi dampak ancaman eksternal. Pada penelitian ini rekomendasi strategi ST yang diberikan adalah menyeleksi target audiens yang melihat iklan berdasarkan range usia, dan jenis kelamin, kemudian implementasi search engine marketing (SEM) dan search engine optimization (SEO) lebih mendalam (S1, T1). Dengan dengan melakukan ini sasaran pasar yang dituju oleh UMKM akan lebih terarah dan tepat sasaran, karena melihat potensi orang-orang yang akan menjadi customer merupakan hal yang sangat krusial. Sedangkan penggunaan SEM dan SEO dapat membantu UMKM medapatkan dan memahami informasi pengguna internet yang dapat dijadikan acuan penentuan pangsa pasar. Informari dari SEM dan SEO berupa perilaku online konsumen, informasi yang dicari oleh pengguna, disonansi konsumen setelah pembelian, mekanisme umpan balik, dan analitik mesin pencari, komitmen merek, loyalitas merek, citra merek, dan kesadaran merekpeng, enalan merek, informasi produk, dan harga produk, ulasan pengguna dan kelangkaan produk, pangsa pasar (Bhandari \& Bansal, 2018). Informasi ini sangat berguna dalam perencanaan strategi pemasaran berbasis media sosial mapun pemasaran digital lainnya.

Strategi selanjutnya adalah membuat hashtag ataupun keyword yang relevan dengan produk yang ditawarkan, membangun brand image (Personal Branding), dan membuat konten iklan yang menarik (S1, T1, T3). Hashtag merupakan metadata tag dengan simbol “\#”. Tujuannya untuk mengelompokkan data. Namun sekarang banyak digunakan untuk pemberian informasi apapun di media sosial (Laucuka, 2018). Oleh karena itu pentingnya membuat hashtag dan keyword yang relevan dengan produk yang ditawarkan dan menjadi kata kunci yang paling sering orang lain orang cari. Misalnya di UKM kuliner menjual maksuba yang merupakan kue khas Palembang, contoh hashtag "\#kuekhaspalembang", "kue" atau dengan keyword "jual kue khas palembang”. Ini didukung dengan hasil penelitian lainnya,yang meneliti 13 sektor industri yang menggunakan keyword untuk aktifitas bisnisnya, hasilnya untuk setiap frase kunci sektor, 10 hasil pay per click (PPC) teratas dicatat, menghasilkan 260 hasil PPC. 260 hasil ini kemudian diperiksa di mesin pencari dan menduduki peringkat 100 teratas (Kritzinger \& Weideman, 2013). Artinya, kesempatan untuk di klik orang yang pertama kali adalah iklan kita. Tentu hal ini sangat membantu UMKM di Palembang agar lebih dikenal secara luas.

Setiap penggunaan teknologi informasi tentu memiliki resiko yang akan dihadapi, oleh karena nya UMKM secara berkala dapat mengganti kata sandi akun media sosial dan akun bank. Lebih mengarahkan konsumen ke transaksi penjualan melalui marketplace ataupun website, dan gunakan rekening bersama (S4, T2). UMKM dapat memanfaatkan penggunaan teknologi Web 2.0 yang mendukung media sosial. Teknologi Web 2.0 menjadi salah satu jenis media yang digunakan dalam strategi pemasaran bagi para wirausahawan yang dianggap efektif karena dampaknya di seluruh dunia. Berbagai macam bisnis yang ditawarkan melalui media sosial saat ini tidak selalu merupakan brand terkenal tetapi juga brand yang baru memulai usaha (Fatonah \& Tunggal Sari, 2018).Hal ini dilakukan untuk meminimalisir tingkat penipuan yang terjadi pada transaksi online dan membangun citra positif dari brand UMKM.

\section{KESIMPULAN}

Penggunaan teknologi informasi sebagai media promosi di sosial media tentu menjadi salah satu teknik pengambilan keputusan yang bertujuan agar usaha kuliner kecil dan menengah di Palembang lebih dikenal lebih luas dan dapat meningkatkan pendapatan. Hasil analisis SWOT merekomendasikan UMKM di Palembang menggunakan strategi diversifikasi dalam melakukan pemasaran ataupun promosi di media sosial.Strategi yang perlu diterapkan adalah ST strategi seperti menyeleksi target audiens yang melihat iklan berdasarkan range usia, dan jenis kelamin, kemudian implementasi search engine marketing (SEM) dan search engine optimization (SEO) lebih mendalam (S1, T1). Membuat hashtag ataupun keyword yang relevan dengan produk yang ditawarkan, membangun brand image (Personal Branding), dan membuat konten iklan yang menarik (S1, T1, T3). Terakhir, Lebih mengarahkan konsumen ke transaksi penjualan melalui marketplace ataupun website, dan gunakan rekening bersama (S4, T2).

Penelitian ini memiliki implikasi secara praktis yakni hasil penelitian dapat dijadikan bahan pertimbangan oleh UMKM dalam merumuskan strategi promosi yang dapat dilakukan di media sosial agar dapat dikenal secara luas dan meningkatkan pendapatan. Penelitian ini juga memberikan implikasi teoritis bahwa analisa SWOT pada penggunaan teknologi informasi sebagai media promosi online dapat dilakukan untuk mengetahui strategi terbaik pada promosi penjualan berbasis teknologi. 


\section{UCAPAN TERIMA KASIH}

Penulis mengucapkan terima kasih kepada Ristek/BRIN yang telah memberikaan dukungan danah penelitian, ucapan terimaksh juga kepada perguruan Tinggi STMIK Palcomtech dan Lembaga LPPM STMIK Palcomtech atas support penelitian ini apresiasi diberikan yang setinggi-tingginya.

\section{DAFTAR PUSTAKA}

Badan Ekonomi Kreatif. 2019. Opus: Ekonomi Kreatif Outlook 2019. In Badan Ekonomi Kreatif. Badan Ekonomi Kreatif.

BHANDARI, R. S., \& BANSAL, A. 2018. Impact Of Search Engine Optimization As A Marketing Tool. Jindal Journal Of Business Research, $7(1)$, 23-36. Https://Doi.Org/10.1177/2278682117754016

DAVID, \& R, F. 2009. Strategic Management: Concepts And Cases (12th Ed.). Ft Prentice Hall.

FATONAH, S., \& TUNGGAL SARI, C. 2018. Swot Analysis Of Web 2.0 Entrepreneur Strategy In Enhancing Competitive Advantage: A Case Study Of Iace Food Start-Up Business In Surakarta. Kne Social Sciences, 3(10), 659671.

Https://Doi.Org/10.18502/Kss.V3i10.3412

GÜREL, E. 2017. Swot Analysis: A Theoretical Review. The Journal Of International Social Research, 10(51), 1307-9581. Https://Doi.Org/Doi: 10.17719/Jisr.2017.1832

HELMS, M. M., \& NIXON, J. 2010. Exploring Swot Analysis - Where Are We Now?: A Review Of Academic Research From The Last Decade. In Journal Of Strategy And Management (Vol. 3, Issue Https:/Doi.Org/10.1108/17554251011064837

KOOK, S. H., KIM, K. H., \& LEE, C. 2017. Dynamic Technological Diversification And Its Impact On Firms' Performance An Empirical Analysis Of Korean It Firms. Sustainability (Switzerland), 9(7). Https://Doi.Org/10.3390/Su9071239

KRITZINGER, W. T., \& WEIDEMAN, M. 2013. Search Engine Optimization And Pay-PerClick Marketing Strategies. Journal of Organizational Computing And Electronic Commerce, 23(3), 273-286. Https://Doi.Org/10.1080/10919392.2013.8081 24

LAUCUKA, A. 2018. Communicative Functions Of Hashtags. Economics And Culture, 15(1), 5662. Https://Doi.Org/10.2478/Jec-2018-0006

MAARIT, T. H., \& HEIKKI, K. 2015. The Usage Of Digital Marketing Channels In Smes. Journal Of Small Business And Enterprise Development, 22(4), 633-651.
Https:/Doi.Org/10.1108/Jsbed-05-2013-0073

NAMUGENYI, C., NIMMAGADDA, S. L., \& REINERS, T. 2019. Design Of A Swot Analysis Model And Its Evaluation In Diverse Digital Business Ecosystem Contexts. Procedia Computer Science, 159, 1145-1154. Https://Doi.Org/10.1016/J.Procs.2019.09.283

ORLANDO, B., RENZI, A., SANCETTA, G., \& CUCARI, N. 2018. How Does Firm Diversification Impact Innovation? Technology Analysis And Strategic Management, 30(4), 391-404.

Https://Doi.Org/10.1080/09537325.2017.1313 405

ŞEKERLI, E. B., \& AKÇETIN, E. 2018. Diversification Strategy In Internet Industry: Case Of Google Inc. Afyon Kocatepe Üniversitesi Sosyal Bilimler Dergisi, 20(3), 271-289. Https://Doi.Org/10.32709/Akusosbil.407405

SINHA, S., \& SINGH, T. 2018. Travel From Traditional Marketing To Digital Marketing. International Journal Of Emerging Research In Management And Technology, 6(11), 173. Https://Doi.Org/10.23956/Ijermt.V6i11.60

SUGIYONO. 2016. Metode Penelitian Kuantitatif, Kualitatif Dan R\&D. Pt Alfabet.

SUGUNA, D., \& SELLADURAI, V. 2019. Swot Analysis Of Digital Marketing In India. International Journal of Multidisciplinary Education And Research, 2(2), 37-40.

ÜLGEN, H., \& MIRZE, S. K. 2010. İşletmelerde Stratejik Yönetim (5th Ed.). Beta Basim Yayim.

UTAMI, Y., NUGROHO, A., \& WIJAYA, A. F. 2018. Perencanaan Strategis Sistem Informasi Dan Teknologi Informasi Pada Dinas Perindustrian Dan Tenaga Kerja Kota Salatiga. Jurnal Teknologi Informasi Dan Ilmu Komputer, 5(3), 253. Https://Doi.Org/10.25126/Jtiik.201853655

YOGA, I. M. S., KORRY, N. P. D. P., \& YULIANTI, N. M. D. R. 2019. Information Technology Adoption On Digital Marketing Communication Channel. International Journal Of Social Sciences And Humanities, 3(2), 95-104. Https://Doi.Org/10.29332/Ijssh.V3n2.297 
Halaman ini sengaja dikosongkan 